\title{
Ateneo bibliográfico: Los médicos de atención primaria nos olvidamos de pensar en el trastorno bipolar
}

Amar K. D, et al. Screening for Bipolar Disorder in a Primary Care Practice. JAMA. 2005;293:956-963

\begin{abstract}
¿Por qué este estudio?
Para pensar que un paciente tiene trastorno bipolar (TB) se necesitan uno o más episodios de síntomas maníacos (ánimo eufórico o irritable, pensamiento acelerado, disminución de la necesidad de dormir, diálogo profuso e involucramiento en actividades riesgosas). La hipomanía y la manía comparten los mismos síntomas pero difieren en la duración del episodio y en su repercusión sobre la vida de los pacientes. El diagnóstico de TB puede ser dificultoso ya que los pacientes tienden a consultar durante los periodos de depresión y no cuando están en la fase maníaca. Además, los médicos de atención primaria no suelen preguntar rutinariamente acerca de episodios maníacos previos frente a un paciente depresivo. Sin embargo, determinar si la depresión es parte de un trastorno bipolar o no, es esencial para el manejo terapéutico de estos pacientes ya que tratarlos con antidepresivos podría precipitar la manía o el ciclado rápido entre manía y depresión, y la no instauración de estabilizadores del ánimo se asocia a un peor pronóstico.
\end{abstract}

\section{El estudio}

Se estimó la prevalencia de trastorno bipolar (TB) en una muestra sistemática de 1146 adultos que esperaban un turno programado con un médico de familia (MF) en una clínica urbana de medicina general de la Ciudad de Nueva York con el cuestionario de Trastornos del Ánimo (en inglés MDQ); se describieron las características demográficas y clínicas, los tratamientos recibidos, el funcionamiento y el daño en la salud de los pacientes cuyo rastreo fue positivo, y se revisaron las notas de evolución de los últimos seis meses en las historias clínicas para ver si los MF habían documentado síntomas de TB y si los habían reconocido como parte de este síndrome.

\section{Resultados}

En 1146 pacientes con una edad media de 51 años, $69,5 \%$ de mujeres, $75 \%$ menos de u $\$ s 12000$ anuales de ingreso y $82,1 \%$ de origen hispánico se documentó una prevalencia de TB de 9,8\% (IC95\% 8,1-11,6). Los síntomas maníacos más reportados fueron irritabilidad extrema, fácil distractibilidad, pensamiento y discurso acelerado. La edad media de reconocimiento de los síntomas fueron los $35+/-13,1$ años, $81 \%$ había buscado ayuda profesional por alguno de estos síntomas y un porcentaje similar había recibido alguna vez diagnóstico de alguna enfermedad mental, sin embargo sólo $8,4 \%$ tenía diagnóstico previo de TB.

Se documentó fuerte asociación entre el diagnóstico de TB y el de depresión mayor, trastornos de ansiedad o del ánimo, abuso de sustancias o pánico. Desde otro punto de vista, $23,3 \%$ de los pacientes con diagnóstico de ansiedad generalizada y $32,3 \%$ de los abusadores de drogas fueron categorizados como bipolares. El $18,8 \%$ de los bipolares presentó ideación suicida, quintuplicando la probabilidad respecto de los no bipolares (IC 2,92-7,49). De los 100 pacientes en quienes se documentó la presencia de TB y que tenían historia clínica, en
96 de estas constaban evoluciones de una o más visitas en los últimos seis meses. El $67,7 \%$ de los pacientes con TB tenían un trastorno o síntoma psiquiátrico anotado (el $49 \%$ era depresión) y no había referencia alguna a TB.

\section{En conclusión}

A pesar de que este estudio fue realizado en EEUU, algunas conclusiones podrían ser extrapoladas a nuestra práctica. Se estimó una prevalencia de TB 9,8\%, más alta que la reportada en estudios previos, lo que podría deberse a una mayor sensibilidad de esta herramienta de rastreo.

Es interesante destacar el subdiagnóstico del TB por parte de los MF, que parecen ser sensibles para detectar trastornos en la esfera mental pero que rara vez incluyen como diagnóstico diferencial al trastorno bipolar. Sería importante tener más presente este diagnóstico cuando detectamos algún trastorno en la esfera mental o abuso de sustancias y recordar interrogar sobre ansiedad, irritabilidad y discurso o pensamiento acelerado, presente o pasado.

El uso eventual de fármacos antidepresivos en pacientes con TB no diagnosticado trae aparejado el riesgo de viraje a manía o hipomanía y, en el largo plazo, acelerar la velocidad de ciclado de la enfermedad y transformar al paciente que antes no lo era en un "ciclador rápido", que tiene menor respuesta a los estabilizadores del ánimo y peor pronóstico. Por lo tanto, la importancia de detectar el TB es que en estos pacientes, el tratamiento antidepresivo siempre debe realizarse con un estabilizador del ánimo estando muy atentos a síntomas y signos de viraje. La tabla 1 describe algunos predictores de enfermedad bipolar que recomendamos sean tenidos en cuenta ante pacientes con un episodio depresivo.

Tabla 1: predictores de enfermedad bipolar.

- Historia familiar de trastorno bipolar.

- Aparición antes de los 25 años.

- Inicio postparto.

- Presencia de síntomas psicóticos.

- Inhibición psicomotriz.

Cuando se trata con antidepresivos a un paciente bipolar que ya está recibiendo estabilizadores del estado de ánimo la duración recomendada de tratamiento es menor que en la depresión unipolar (seis meses para los cicladores lentos y seis semanas para los rápidos). Los antidepresivos que tendrían menor riesgo de viraje son el bupropion y los inhibidores de la recaptación de la serotonina. Si hay mínima duda de bipolaridad, no debería instituirse fluoxetina ya que tiene una vida media muy prolongada y el paciente puede permanecer maníaco durante varias semanas.

Gabriel Knalevsky y Esteban Kuten [ Servicio de Medicina Familiar y Comunitaria del Hospital Italiano de Buenos Aires. gabriel.knallevsky@ hospitalitaliano.org.ar; esteban.kuten@ hospitalitaliano.org.ar ]

Knalevsky G, Kuten E. Los médicos de atención primaria nos olvidamos de pensar en el trastorno bipolar. Evid. actual. práct. ambul; 10(3): 78, May.Jun.2007. Comentado de: Amar K. D, et al. Screening for Bipolar Disorder in a Primary Care Practice. JAMA. 2005;293:956-963.

Bibliografía recomendada

Jufe, Gabriela. Psicofarmacología práctica. Buenos Aires : Polemos, 2001

Wikinski, Silvia. El Tratamiento Farmacologico En Psiquiatria. Editorial: Panamericana. ISBN: 950062439

* El MDQ posee una sensibilidad de $28 \%$ y una especificidad del $97 \%$ cuando es utilizado en la población general y $73 \%$ y $90 \%$, respectivamente, cuando es utilizado en población seleccionada en clínicas psiquiátricas. Se lo considera positivo cuando el paciente presentó siente síntomas maníacos en toda su vida, varios síntomas concurrentes y daño funcional asociado a este cuadro calificado como moderado o serio. 